\title{
The Use of the Hemostatic Agent Zhelplastan in Combination with a Granulated Sorbent in the Treatment of Patients with Mallory-Weiss Syndrome
}

\author{
Evgeniy F. Cherednikov ${ }^{1 *}$, PhD, ScD; Igor S. Yuzefovich ${ }^{1}$, PhD; Yuri V. Maleev ${ }^{2}, \mathrm{PhD}, \mathrm{ScD}$; \\ Sergey V. Barannikov ${ }^{1}, \mathrm{PhD}$; Tatyana E. Litovkina ${ }^{3}, \mathrm{PhD}$; Galina V. Polubkova ${ }^{1}, \mathrm{PhD}$; \\ Evgeniy S. Ovsyannikov ${ }^{1}, \mathrm{PhD}, \mathrm{ScD}$ \\ ${ }^{1}$ Voronezh State Medical University named after N. N. Burdenko \\ ${ }^{2}$ Voronezh Basic Medical College \\ ${ }^{3}$ Voronezh City Clinical Emergency Hospital №1 \\ Voronezh, the Russian Federation
}

\begin{abstract}
Background: Mallory-Weiss syndrome (MWS) is one of the common causes of acute upper gastrointestinal bleeding. The aim of our research was to develop a method for the treatment of MWS, which would improve the efficiency of local hemostasis, reduce the risk of re-bleeding and shorten the treatment time.

Methods and Results: The study involved 102 patients with MWS. All patients were divided by random sampling into two groups: the main group (MG) and control group (CG). Patients of both groups were comparable in age, gender, concomitant diseases, type of bleeding, size of bleeding defect, and duration of observations.

The MG included 52 patients, who were given the developed method of MWS treatment. Patients with ongoing bleeding were treated with a combined method of endoscopic hemostasis: active bleeding was initially stopped by infiltration or coagulation (argonplasma coagulation was preferred), and then to increase the reliability of hemostasis and prevent the resumption of bleeding, powdered Zhelplastan $0.2 \mathrm{~g}$ was applied to the rupture area with an insufflator, followed by Sephadex G-25 0.3 g (Patent RF №2633925). In patients with signs of unstable hemostasis, the developed method of cytoprotective action on a clot or thrombosed vessel was used by applying a local hemostatic, Zhelplastan $0.2 \mathrm{~g}$, to the defect area in combination with a granular sorbent, Sephadex G-25 $0.3 \mathrm{~g}$, during therapeutic endoscopy to prevent the resumption of bleeding. In patients with stable stopped bleeding, a hemostatic powdered Zhelplastan was applied to the defect area using an endoscope in combination with Sephadex G-25, according to the developed method.

In the $C G(n=50)$, well-known methods of arresting endoscopic bleeding (pricking with aminocaproic acid, vasoconstrictors, argon-plasma coagulation, etc.) were used without local hemostatics and granular sorbents.

Summing up the results of patients with Mallory-Weiss syndrome in the compared groups, in the MG final hemostasis was performed in 51(98.1\%) patients. In the MG, bleeding resumed in 1(1.9\%) patient. There were no emergency operations or deaths. In the CG, the bleeding was finally stopped in $43(86 \%)$ patients, and it resumed in $7(14 \%)$ patients. Emergency surgery was required for $1(2 \%)$ patient. In the $C G$, the mortality rate was $4 \%$.

Conclusion: In MWS, the use of the developed method of endoscopic treatment, including pneumoinsufflation of a powdered hemostatic agent in combination with a granular sorbent, against the background of conservative therapy, improved the results of treatment, increased the reliability of local hemostasis, reduced the number of recurrent bleedings, and excluded emergency operations.(International Journal of Biomedicine. 2021;11(2):160-163.)
\end{abstract}

Key Words: Mallory-Weiss syndrome • endoscopic treatment • pneumoinsufflation • Zhelplastan • Sephadex G-25

For citation: Cherednikov EF, Yuzefovich IS, Maleev YuV, Barannikov SV, Litovkina TE, Polubkova GV, Ovsyannikov ES.The Use of the Hemostatic Agent Zhelplastan in Combination with a Granulated Sorbent in the Treatment of Patients with MalloryWeiss Syndrome.International Journal of Biomedicine. 2021;11(2):160-163. doi:10.21103/Article11(2)_OA7

Abbreviations: APC, argon-plasma coagulation; GEJ, gastroesophageal junction; MWS, Mallory-Weiss syndrome. 


\section{Introduction}

The problem of treating patients with gastroduodenal bleeding remains one of the most acute in emergency surgery. The number of patients with MWS does not decrease and even tends to increase. The leading role in the treatment of patients with MWS belongs to therapeutic endoscopy. ${ }^{(1-8)}$

The number of relapses of bleeding in MWS reaches $42 \%$, and postoperative mortality is $10 \%-17 \%$. At the same time, MWS patients are of working age, which indicates the high social and economic significance of this disease. These circumstances demonstrate the need to develop new highly effective treatments for MWS patients. ${ }^{(9-12)}$ The use of local hemostatic agents in combination with a granular sorbent seems to be promising. ${ }^{(13-19)}$

The aim of our research was to develop a method for the treatment of MWS, which would improve the efficiency of local hemostasis, reduce the risk of re-bleeding and shorten the treatment time.

\section{Materials and Methods}

A clinical study was conducted in the Voronezh City Specialized Center for the treatment of patients with gastrointestinal bleeding. The study involved 102 patients (82[80.4\%] men and 20[19.6\%] women) with MWS. The peak incidence in men was at the age of 32-52 years. In women, the peak incidence was at 33-53 years and at 60-75 years.

Upon admission, all patients underwent emergency esophagogastroduodenoscopy. Bleeding defects in MWS were distributed according to their localization as follows: GEJ - 88(86.3\%), stomach - 3(2.9\%), esophagus - 11(10.8\%). Defects in the GEJ were located on the right wall in $39(38.2 \%)$ patients, on the posterior wall - in $35(34.3 \%)$ patients, on the anterior wall - in 16(15.7\%), and on the left wall - in 12(11.8\%).

The length of the defects varied in the range of 0.4-2.7 $\mathrm{cm}$. We classified the defects into 3 categories, according to size: small $(<1 \mathrm{~cm})$, medium $(1.0-2.5 \mathrm{~cm})$, and large $(>2.5$ $\mathrm{cm})$. Small defects were found in $77(75.5 \%)$ patients, medium - in $23(22.5 \%)$, and large defects were rarely observed - in only $2(2 \%)$ patients.

Regarding depth, defects were within the mucous layer (Stage I) in $40(39.2 \%)$ patients, mucous-submucosal layer (Stage II) - in 57(55.9\%), and defects with damage to the muscle base (Stage III) - in only $5(4.9 \%)$ patients.

Defects were single in $72 / 70.6 \%$ of cases. Multiple defects were less common - in $30 / 29.4 \%$ of patients. In patients with a sliding hiatal hernia, multiple ruptures were more common. The number of breaks and their length did not affect the volume of blood loss.

According to the endoscopic picture, patients with MWS were divided as follows: ongoing bleeding (10/9.8\%); a thrombosed vessel or clot (signs of unstable hemostasis) $(57 / 55.9 \%)$; visible hematin spots (signs of stopped bleeding) $(35 / 34.3 \%)$.

The severity of blood loss was evaluated according to the classification of A.I. Gorbashko $(1982)^{(20)}$ : mild degree was observed in 54(52.9\%) patients, moderate degree - in
$34(33.4 \%)$ and severe degree - in 14(13.7\%) patients.

All patients were divided by random sampling into two groups: the main group (MG) and control group (CG).

The MG included 52 patients, who were given the developed method of MWS treatment. Patients with ongoing bleeding ( 6 people) were treated with a combined method of endoscopic hemostasis: active bleeding was initially stopped by infiltration or coagulation (APG was preferred), and then to increase the reliability of hemostasis and prevent the resumption of bleeding, powdered Zhelplastan $0.2 \mathrm{~g}$ was applied to the rupture area with an insufflator, followed by Sephadex G-25 0.3g (Patent RF №2633925).

In patients with signs of unstable hemostasis $(n=28)$, the developed method of cytoprotective action on a clot or thrombosed vessel was used by applying a local hemostatic, Zhelplastan $0.2 \mathrm{~g}$, to the defect area in combination with a granular sorbent, Sephadex G-25 0.3 g, during therapeutic endoscopy to prevent the resumption of bleeding. At the same time, patients with localized ruptures along the right wall of the GEJ were identified and assigned to the group with a high risk of recurrent bleeding. These patients first underwent APC of the thrombosed vessel, and then also pneumoinsufflation of Zhelplastan and Sephadex G-25 to prevent recurrence of bleeding.

In patients with stable stopped bleeding $(n=18)$, a hemostatic powdered Zhelplastan was applied to the defect area using an endoscope in combination with Sephadex G-25, according to the developed method. Repeated therapeutic endoscopy in the MG patients was performed after 4-5 days.

Patients of both groups were comparable in etiology of bleeding, age, gender, concomitant diseases, type of bleeding, size of bleeding defect, and duration of observations (Table 1),

Table 1.

Clinical characteristics of the study groups

\begin{tabular}{|l|c|c|c|c|}
\hline \multicolumn{1}{|c|}{ Variable } & $\begin{array}{c}\text { MG } \\
(\mathrm{n}=52)\end{array}$ & $\begin{array}{c}\text { CG } \\
(\mathrm{n}=50)\end{array}$ & $P$ & $\begin{array}{c}\text { Total } \\
(\mathrm{n}=102)\end{array}$ \\
\hline Age & $\begin{array}{c}43.0 \\
(32.0 ; 57.0)\end{array}$ & $\begin{array}{c}42.5 \\
(33.0 ; 53.0)\end{array}$ & $>0.05$ & $\begin{array}{c}43.0( \\
32.5 ; 56.0)\end{array}$ \\
\hline Men & $43(82.7 \%)$ & $39(78.0 \%)$ & $>0.05$ & $82(80.4 \%)$ \\
\hline Women & $9(17.3 \%)$ & $11(22.0 \%)$ & $>0.05$ & $20(19.6 \%)$ \\
\hline \multicolumn{5}{|c|}{ Type of bleeding } \\
\hline Ongoing bleeding & $6(11.5 \%)$ & $4(8.0 \%)$ & $>0.05$ & $10(9.8 \%)$ \\
\hline $\begin{array}{l}\text { Unstable hemostasis } \\
\text { (clot or trombosed } \\
\text { vessel). }\end{array}$ & $28(53.9 \%)$ & $29(58.0 \%)$ & $>0.05$ & $57(55.9 \%)$ \\
\hline $\begin{array}{l}\text { Stable stopped } \\
\text { bleeding (hematin on } \\
\text { the defect base) }\end{array}$ & $18(34.6 \%)$ & $17(34.0 \%)$ & $>0.05$ & $35(34.3 \%)$ \\
\hline \multicolumn{5}{|c|}{ Depth of defects } \\
\hline Stage I & $19(36.5 \%)$ & $21(42.0 \%)$ & $>0.05$ & $40(39.2 \%)$ \\
\hline Stage II & $30(57.7 \%)$ & $27(54.0 \%)$ & $>0.05$ & $57(55.9 \%)$ \\
\hline Stage III & $3(5.8 \%)$ & $2(4.0 \%)$ & $>0.05$ & $5(4.9 \%)$ \\
\hline \multicolumn{5}{|c|}{ The severity of blood loss (A. I. Gorbashko, 1982) } \\
\hline Mild & $25(48.1 \%)$ & $29(58.0 \%)$ & $>0.05$ & $54(52.9 \%)$ \\
\hline Moderate & $19(36.5 \%)$ & $15(30.0 \%)$ & $>0.05$ & $34(33.4 \%)$ \\
\hline Severe & $8(15.4 \%)$ & $6(12.0 \%)$ & $>0.05$ & $14(13.7 \%)$ \\
\hline
\end{tabular}


In the CG $(n=50)$, well-known methods of arresting endoscopic bleeding (pricking with aminocaproic acid, vasoconstrictors, coagulation, APC, etc.) were used without local hemostatics and granular sorbents.

The complex therapy of patients of both groups included antacids, proton pump inhibitors, infusion-transfusion, general hemostatic and symptomatic therapy.

The main criteria in assessing the results of treatment were both clinical and endoscopic indicators: the timing of final hemostasis, the frequency of rebleeding, dynamic monitoring of the size of bleeding defects, the quality of healing of defects, the presence of urgent surgical interventions, the mortality rate, and the length of hospital stay.

Statistical analysis was performed using Microsoft Excel software package. For descriptive analysis, results are presented as mean \pm standard deviation (SD), median (Me), interquartile range (IQR), minimum and maximum values. For data with normal distribution, inter-group comparisons were performed using Student's t-test. Wilcoxon rank sum test was used to test for difference in medians. Group comparisons with respect to categorical variables were performed using Fisher's exact test. A probability value of $P<0.05$ was considered statistically significant.

\section{Results}

Of the total number of MWS patients, active bleeding was observed in 10 of them. In patients of the MG with ongoing bleeding $(n=6)$, the effectiveness of primary endoscopic hemostasis was $100 \%$. After the immediate bleeding was stopped, all patients in the MG were prevented from rebleeding by the developed method. It should be noted that none of the patients resumed bleeding, and their primary endoscopic hemostasis was reliable and final. In MG, there were no fatal outcomes or operations in patients with ongoing bleeding.

In the CG of patients with ongoing bleeding $(n=4)$, primary endoscopic hemostasis was also effective in all patients, but recurrent bleeding was observed in 2 patients: one patient with bleeding from a rupture of the GEJ along the right wall underwent emergency surgery-stitching of the bleeding defect. The patient was discharged with improvement. In another patient, recurrent bleeding was stopped endoscopically. There were no fatal outcomes in patients with ongoing bleeding in the CG.

Signs of unstable hemostasis (clot or thrombosed vessel) were detected in 57 patients. In the MG, 28 patients underwent preventive endoscopic treatment for recurrent bleeding using the developed technique. Resumption of bleeding was observed in 1 patient with a deep rupture (Stage III) located on the right wall of the GEJ. Repeated endoscopic hemostasis in this patient was performed by a developed combined method: first, APC of the thrombosed vessel, and then application of Zhelplastan and sorbent. There were no emergency operations or deaths in this group.

When monitoring 29 patients of the CG with signs of unstable hemostasis, a recurrence of bleeding was observed in 5 patients, which was stopped by traditional methods of endoscopic hemostasis. No surgical treatment was required. In the CG, 2 patients died: 1 . Patient K., 51 years old, suffering from chronic alcoholism; death occurred as a result of acute blood loss on the background of alcoholic illness. 2. Patient T., 85 years old; the fatal outcome was associated with the progression of the underlying disease against the background of anemia.

In the patients with stable stopped bleeding (MG and $\mathrm{CG})$, a recurrence of bleeding was not detected; there were no deaths or operations in both groups.

Summing up the results of patients with Mallory-Weiss syndrome in the compared groups, in the MG final hemostasis was performed in 51(98.1\%) patients. In the $\mathrm{MG}$, bleeding resumed in $1(1.9 \%)$ patient. There were no emergency operations or deaths. In the $\mathrm{CG}$, the bleeding was finally stopped in $43(86 \%)$ patients, and it resumed in $7(14 \%)$ patients. Emergency surgery was required for $1(2 \%)$ patient. In the $\mathrm{CG}$, the mortality rate was $4 \%$.

Analysis of the causes of recurrent bleeding in patients with MWS showed that the depth of the bleeding defect and its localization are important for endoscopic hemostasis. In all patients, relapses of bleeding occurred with deep ruptures penetrating through the entire muco-submucosal base and having an esophageal-gastric localization with a predominant location on the right wall, where large vessels pass. This arrangement of bleeding defects presents certain technical difficulties during therapeutic endoscopy, which affects the quality of hemostasis.

During clinical studies, it was noted that in all patients of the MG, after pneumoinsufflation of powdered Zhelplastan and Sephadex G-25, a protective, insoluble, hydrogel layer with hemostatic and cytoprotective properties was formed on the surface of bleeding defects. This hydrogel hemostatic composition, due to its adhesive properties, lay tightly on the bleeding defect and protected it from the effects of aggressive gastric juice, while creating conditions for the active course of reparative processes.

During repeated examinations during esophagogastroduodenoscopy, we found that the hydrogel composition was retained on the surface of the defect for up to 4-5 days. At the same time, the reparative process in the MG with such local treatment was faster and better than in the CG. Thus, the healing time of defects in the MG was $4.7 \pm 0.25$ days. In the $\mathrm{CG}$, the healing time of defects was $9.7 \pm 0.55$ days (Table 2 ).

Table 2.

Results of treatment of patients with MWS in the study groups

\begin{tabular}{|l|c|c|c|}
\hline \multicolumn{1}{|c|}{ Variable } & $\begin{array}{c}\mathrm{MG} \\
(\mathrm{n}=52)\end{array}$ & $\begin{array}{c}\mathrm{CG} \\
(\mathrm{n}=50)\end{array}$ & $P$-value \\
\hline Final hemostasis & $51(98.1 \%)$ & $43(86.0 \%)$ & 0.0296 \\
\hline Recurrent bleedings & $1(1.9 \%)$ & $7(14.0 \%)$ & 0.0296 \\
\hline Emergency surgery & - & $1(2.0 \%)$ & \\
\hline Mortality rate & - & $2(4.0 \%)$ & \\
\hline Healing time of defects, days & $4.7 \pm 0.25$ & $9.7 \pm 0.55$ & 0.0000 \\
\hline Epithelialization of defects & $49(94.2 \%)$ & $32(64.0 \%)$ & 0.0002 \\
\hline Length of hospital stay, days & $5.0 \pm 0.5$ & $8.0 \pm 1.2$ & 0.0000 \\
\hline
\end{tabular}

It is important to note that in the case of ruptures of the mucosa and submucosal layer), the healing of defects in the treatment with Zhelplastan and Sephadex G-25 occurred by 
epithelialization without scar formation. The use of Zhelplastan in combination with Sephadex G-25 allowed achieving a final termination of bleeding in the MG in $98.1 \%$ of cases (compared to $86.0 \%$ of patients in the CG; $P=0.0296$ ), and also led to a decrease in the frequency of recurrent bleeding from $14.0 \%$ to $1.9 \%(P=0.0296)$ (Table 2$)$.

In conclusion, in MWS, the use of the developed method of endoscopic treatment, including pneumoinsufflation of a powdered hemostatic agent in combination with a granular sorbent, against the background of conservative therapy, improved the results of treatment, increased the reliability of local hemostasis, reduced the number of recurrent bleedings, and excluded emergency operations.

\section{Sources of Funding}

This work was partially supported by the Council on Grants of the President of the Russian Federation for State Support of Young Scientists and Leading Scientific Schools (Grant MK-1069.2020.7).

\section{References}

1. Budnevsky AV, Cherednikov EF, Popov AV, Ovsyannikov ES, Kravchenko AY, Fursov KO. A Complex Multidisciplinary Approach to Prevention Gastro-duodenal Bleeding in Patients of General Hospital. International Journal of Biomedicine. 2017;7(3):204-207. doi: 10.21103/Article7(3) OA8

2. Cherednikov EF, Budnevsky AV, Popov AV, Fursov KO. A new opinion on gastroduodenal bleeding preventon in patients with somatic pathology. The EPMA Journal. 2017;8(S1):46.

3. Cherednikov E F, Chernyh AV, Maleev YuV, Popov AV, Stekolnikov VV. [Topographical and anatomical prerequisites for the development of Mallory-Weiss syndrome]. Bulletin of the Russian Military Medical Academy. 2015;(S2):153-154. [Article in Russian].

4. Cherednikov EF, Deryaeva OG, Adianov VV, Ovchinnikov IF, Popov AV. [Modern directions of prevention and treatment of patients with gastrointestinal bleeding in the center]. System Analysis and Management in Biomedical Systems. 2014;13(2):426-433. [Article in Russian].

5. Cherednikov EF, Maleev YuV, Chernyh AV, Litovkina TE, Bondarenko AA, Cherednikov EE, Popov AV. [Current views on the diagnosis, treatment, and prevention of ruptured hemorrhagic syndrome (Mallory-Weiss syndrome)]. Journal of New Medical Technologies. 2016;23(4):161-172. [Article in Russian].

6. Baev VE, Kravets BB, Cherednikov EF. [Diagnostics of ulcerative forms of stomach cancer]. Voronezh. 2003:112. [In Russian].

7. Cherednikov EF, Barannikov SV, Maleev YuV, Fursov KO, Litovkina TE, Zakurdaev EI. [Experimental justification of the use of biologically active draining sorbent and plasma enriched by thrombocytes in treatment of bleeding defects of the stomach]. Journal of New Medical Technologies. 2017;24(2):114-118. [Article in Russian].

8. Cherednikov EF, Batkaev AR, Baev VE. The Reparative

*Corresponding author: Evgeniy $S$. Ovsyannikov, $P h D, S c D$ Department of faculty therapy, Voronezh State Medical University named after N.N. Burdenko.Voronezh, Russia.E-mail: ovses@ yandex.ru regeneration of erosive-ulcerative lesions of the stomach and duodenum in the local treatment of hydrophilic granular sorbents. System Analysis and Management in Biomedical Systems. 2005;4(2):224-225. [Article in Russian].

9. Cherednikov EF, Maleev YuV, Chernyh AV, Litovkina TE, Cherednikov EE, Shevtsov AN. [Modern views on the etiology and pathogenesis of ruptured hemorrhagic syndrome (MalloryWeiss syndrome)]. Journal of anatomy and Histopathology. 2016;5(1):86-98. [Article in Russian].

10. Adianov VV, Cherednikov EF. [Optimizing treatment of gastroduodenal bleeding in patients with high surgical risk]. System Analysis and Management in Biomedical Systems. 2014;13(4):841-846. [Article in Russian].

11. Deryaeva OG, Cherednikov EF. [Multimodality therapy of erosiveulcer gastroduodenal bleeding by patients in a multidisciplinary hospital]. System Analysis and Management in Biomedical Systems. 2014; 13(3):725-730. [Article in Russian].

12. Cherednikov EF, Barannikov SV, Fursov KO, Polubkova GV, Danilenko VI, Stepanov DS. [Healing of bleeding experimental defects of the stomach with topical anilovin and platelet-rich plasma]. Journal of Volgograd State Medical University. 2017;2(62):130-133. [Article in Russian].

13. Cherednikov EF, Barannikov SV, Yuzefovich IS, Polubkova GV, Maleev YuV, Volkova IV, et al. Innovative Endoscopic Technologies in the Complex Treatment of Patients with Unstable Stopped Gastroduodenal Bleeding. International Journal of Biomedicine. 2021;11(1):24-28. doi:10.21103/ Article11(1)_OA4

14. Cherednikov EF, Barannikov SV, Maleev YuV, Fursov KO, Litovkina TE, Zakurdaev EI, Ovsyannikov ES. Experimental justification of using Aseptisorb-A and platelet-rich plasma in endoscopic treatment of mold bleeding stomach defects. International Journal of Biomedicine. 2017;7(4):298-301. doi: 10.21103/Article7(4)_OA5

15. Cherednikov EF, Barannikov SV, Romantsov MN, Popov AV. New aspects of preventive endoscopic hemostasis in the treatment of peptic ulcer bleeding in the experimental condition. The EPMA Journal. 2017; 8(S1):45.

16. Cherednikov EF, Barannikov SV, Zhdanov AI, Moshurov IP, Polubkova GV, Maleev YuV, et al. Combimed Use of Biologically Active Hemostatic and Granulated Sorbent in Endoscopic Cytoprotective Hemostasis in Patients with Bleeding Gastroduodenal Ulcers. International Journal of Biomedicine. 2020;10(2):129-132. doi: 10.21103/Article10(2)_OA8

17. Cherednikov EF, Glukhov AA, Romantsov MN, Maleev YuV, Barannikov SV, Shkurina IA, et al. Hemostatic Agents in Combination with Diovine for Local Treatment of Simulated Bleeding Gastric Ulcers. International Journal of Biomedicine. 2020;10(2):138-141. doi: 10.21103/Article10(2)_OA10

18. Cherednikov EF, Kashurnikova MA, Romantsov MN, Barannikov SV, Bolkhovitinov AE, Gaponenkov DG, Lyubimov $\mathrm{PYu}$. [Experimental study of new means of local hemostasis in the treatment of ulcerative bleeding]. Scientific and Medical Bulletin of the Central Chernozem Region. 2016;(65):27-33. [Article in Russian].

19. Romantsov MN, Cherednikov EF, Danilenko VI, Stepanov DS, Fursov K O, Deryaeva AG. [Morphological Characteristics of Processes of Simulated Bleeding Gastric Defects Reparation in Treatment with Gelplastan and Diovin]. Journal of Anatomy and Histopathology. 2017;6(1):81-86. [Article in Russian].

20. Gorbashko AI. Diagnostics and treatment of blood loss. Moscow: Meditsina. 1982:224. [In Russian]. 